\title{
VIRTUAL TOURS AND INFORMATIONAL MODELS FOR IMPROVING TERRITORIAL ATTRACTIVENESS AND THE SMART MANAGEMENT OF ARCHITECTURAL HERITAGE: THE 3D-IMP-ACT PROJECT
}

\author{
M. De Fino ${ }^{1, *}$, C. Ceppi ${ }^{1}$, F. Fatiguso ${ }^{1}$ \\ ${ }^{1}$ Department of Civil, Environmental, Land, Construction and Chemistry, Polytechnic of Bari, Via Orabona 4, 70125, Bari, Italy \\ (mariella.defino, fabio.fatiguso)@poliba.it, ceppicla@gmail.com
}

Commission II - WG II/8

KEY WORDS: Architectural Heritage, Virtual Tours, 3D models, Web-GIS platform, Conservation and Promotion

\begin{abstract}
:
The promotion and dissemination of architectural heritage for cultural enhancement and touristic enjoyment are increasingly focused on innovative ICTs, including 3D Geographic Information Systems, photorealistic models and scenes, and VR/AR immersive digital environments, which enable the interaction of visitors with a variety of informational contents, both educational and specialist. Within the above-mentioned framework, this paper will firstly outline the general objectives of the project "3D-IMP-ACT", which has been funded under the international cooperation programme IPA CBC Interreg Italy-Albania-Montenegro. In this research, some ICT tools are tested and validated to create "virtual networks" of international ancient architectures and sites, based on the identification of "physical networks" of common historic, environmental and technical characteristics and infrastructural connections, in order to address coordinated strategies and transversal policies for development and management. Then, the paper will describe and discuss some results from the design and implementation of the project WebGIS system, which integrates virtual tours of $360^{\circ}$ panoramas, $3 \mathrm{D}$ models from photomodelling of pictures taken by drones, multimedia contents, and 2D/3D historic evolution schemes within a single platform, where the users are supported in recognizing and exploring the tangible and intangible correspondences among the project pilot-cases. In conclusion, some remarks will be proposed on the potential benefits of the platform as an expert system which supports the technical assessment and control of architectural heritage toward maintenance, refurbishment and conservation.
\end{abstract}

\section{INTRODUCTION}

The promotion and dissemination of historical-architectural sites and buildings for cultural enhancement and touristic enjoyment are nowadays increasingly focused on innovative enabling Information and Communication Technologies (ICT) for the restitution of so-called Digital Heritage (DH).

In particular, the most common acquisition techniques, from topography to laser scanning, and from terrestrial to aerial digital photogrammetry, including by Unmanned Aerial Vehicles (UAVs), has the potential to address a variety of 3D representation solutions, e.g. $360^{\circ}$ panoramic scenes, coloured point clouds and texturized polygonal meshes, as well as geometry modelling and surface rendering by Computer Assisted Design (CAD) tools. Nevertheless, these solutions might be visualized by different systems, such as Geographical Information Systems (GIS), virtual tours, virtual reality (VR) environments and augmented reality (AR) contents. As a result, increasing levels of complexity are available, from simple remote consultation available for $\mathrm{PC} /$ tablet/smartphone to Oculus-based visualization, as well as simulation in projection rooms, also known as "caves" or "cubes", where the users can experience sensorial immersion.

Within the prolific and dynamic scientific literature on the abovementioned topics, the most interesting field for the present study, also in the light of its recent evolution, concerns the research and applications of photoscanning-based digital models and environments that are integrated in platforms for data storage, consultation and management, particularly within geographic reference systems. In fact, such integration and application are able to address two correlated and complementary requirements for cultural enhancement and touristic enjoyment. The first is the perception of cultural assets through an immersive photorealistic environment, which seems more appropriate and appealing in representing complex architectural-archaeological shapes, surfaces and spaces than CAD-based solutions. The second is the vision of cultural assets as nodes of networks that mark a variety of connections and correspondences which amplify the territorial attractiveness and smart management of single sites/architectures.

Specifically, some publications are very inspiring in the field of $2 \mathrm{D}$ and 3D GIS for the VR/AR exploration of coloured point clouds and texturized polygonal meshes (Ferreira, 2018; Li, 2017; Campanaro et al., 2016), which have different purposes, ranging from being educational and entertaining (Scianna, La Guardia, 2018; Marquez et al., 2017; Malfitana et al., 2016) to being tools of systemic classification for strategic management and control (Barelli et al., 2017; Trizio et al., 2018; Arca et al., 2018; Von Schwerin et al., 2011; Vacca et al. 2018).

Nevertheless, the state-of-the-art leaves some research lines open toward fruition at multiple levels. Firstly, the multi-scale representation, from the territorial setting to the indoor navigation, is still under development, whereas most experiences refer to architectural, or more frequently archaeological, sites with $3 \mathrm{D}$ photorealistic reconstruction of the external volumes and surfaces. Secondly, the multi-functionality should be improved toward the development of tools that, beyond cultural promotion and enhancement, are able to support decision-making processes in terms of the specialized assessment, diagnosis and control of the state of conservation of the built heritage. 
In light of the above-mentioned issues, the possibility of exploiting the potential of enabling ICTs, both for touristic and technical purposes, seems highly desirable, in order to interrelate the knowledge domains from different profiles of users - from "simple" visitors to "expert" scholars - and for a network of assets with similar cultural and/or technical characteristics. Within the above-mentioned framework, the project "3D-IMP-ACT", funded under the international cooperation programme IPA CBC Interreg Italy-AlbaniaMontenegro, aims at testing and validating some ICT tools, in order to create "virtual networks" of international ancient architectures and sites, based on the identification of "physical networks" of common historic, environmental and technical characteristics and infrastructural connections, and thereby address coordinated strategies. In particular, the paper will describe and discuss some preliminary results from the design and implementation of the project WebGIS system, which integrates virtual tours of $360^{\circ}$ panoramas, 3D models from photomodelling, multimedia contents and 2D/3D historic evolution schemes within a single platform, in which the users are supported in recognising the tangible and intangible correspondences among the pilot-cases.

\section{METHODOLOGY}

As outlined in the introduction, the creation of "virtual networks" of international ancient architectures and sites, with specific reference to the territories involved in the IPA CBC - Italy (Apulia Region), Albania and Montenegro Programme, has been developed, starting from the identification of "physical networks" of common historic, environmental and technical characteristics and infrastructural connections, by means of a WebGIS platform, according to the methodological framework in Figure 1. More specifically, the 3D-IMP-ACT WebGIS environment incudes three categories of entities:

- Paths (P), identified as lines;

- Architectures (A), identified as points;

- Sites (S), identified as polygons.

The Paths (P1, .., Pn) represent the system of "slow" connections - mainly pedestrian and cyclic routes - linking the architectures and sites on the territory, not only in a tangible way but also conceptually, as coming from ancient routes and traces. Thus, they act as entities of historical-cultural relations among the pilot-cases, enabling the recovery of their identity as a system toward sustainable enjoyment. The Architectures are classified according to homogeneous categories $(\mathrm{A} 1, \ldots, \mathrm{An})$, based on their typology (castles, churches, palaces ...), with the intention of grouping the potential case studies accordingly $(\mathrm{A} 1.1, \ldots$, A1.m, ..., An.1, ..., An.m). The Sites are classified according to homogeneous categories, too, $(\mathrm{S} 1, \ldots, \mathrm{Sn})$, based on their typology (archaeological parks, historic centres, hypogeal settlements ...).

The core of the WebGIS is the Geo-DataBase (Geo-DB) Post GIS, which relates the entities according to both logical and spatial keys. For each pilot-case -for both architectures and sites - the WebGIS enables the interrogation of historical and architectural information, in the form of texts, photos, drawings, and the consultation of a series of digital external web products, all of which are produced within the project and referenced within an immersive virtual tour of $360^{\circ}$ panoramic scenes of indoor spaces and outdoor areas. In particular, the digital contents might be implemented as hot spots or highlights.
The hot spots, at the beginning of the tour if general or at particular points if specific, concern the following aspects: Schemes and models on the historical evolution (Timeline); Multimedia products (Media); 3D reproductions of significant portions $(3 D)$; and, thematic maps and experimental data on the state of conservation (Diagnostic).

The highlights are specifically located across some relevant elements for the reference category of architecture (e.g. HA1.1, ..., HA1.n for the category of Architectures A1) or site (e.g. HSm. $1, \ldots$, HSm.n for the category of Site Sm). They describe some typological invariants (e.g. towers, drawbridge, terre-plein ... for the castles, basilicas, tombs, thermal structures ... for the archaeological sites). Each highlight displays a short descriptive fact-sheet and a list of all the same highlights in the WebGIS database, as it relates to both a single case study and all the project case studies. In the latter scenario, this also enables the connection with the related virtual tour. Consequently, the highlights represent the transition key from one architecture/site to the next, guiding the users through the navigation of the virtual network. The above-mentioned key is the most user-friendly way for the touristic visitors to explore the platform.

Nevertheless, since all the virtual tours, as well as the digital contents from the hot spots and the highlights, are stored as records of the WebGIS environment, the expert users who are more interested in specialized data, such as architectural details, three-dimensional representations and thematic diagnostic maps, might interrogate the database according to their needs, as support for assessment and diagnosis. In fact, the system platform offers high-resolution photorealistic reproductions of surfaces and spaces, enabling a reliable on-site-like investigation of constructional-technical characteristics and decay patterns. Furthermore, it provides a structured inventory of multidisciplinary information for integrated and coordinated management by all the different professionals who are involved in the process of restoration, refurbishment and maintenance.

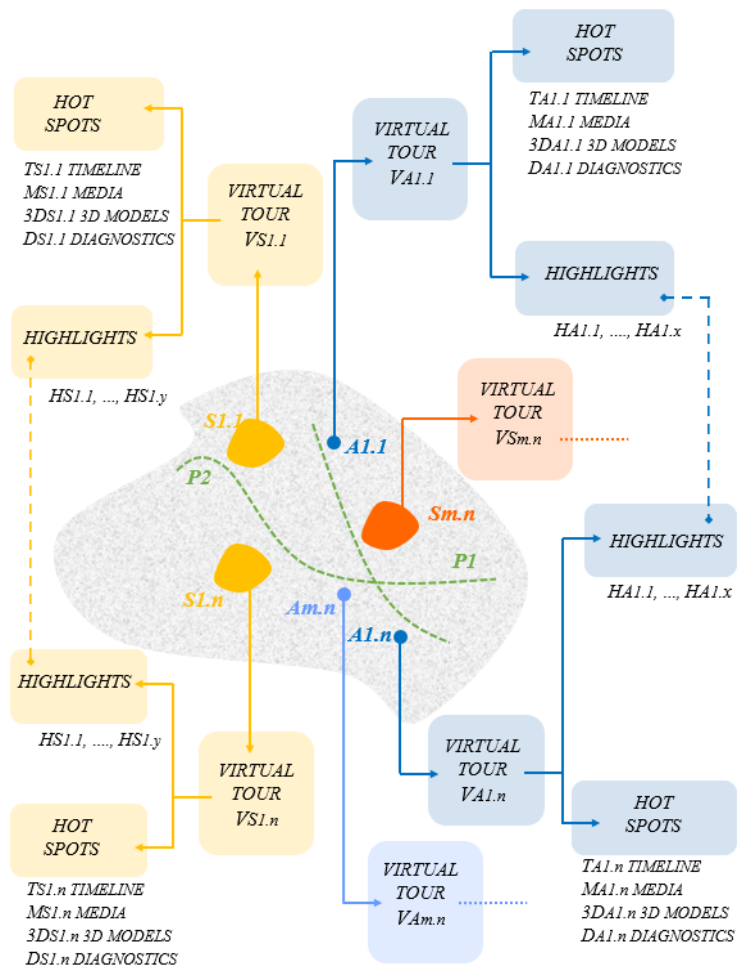

Figure 1. Methodological framework. 


\section{TOOLS AND TECHNIQUES}

Based on the above-described methodological framework, some specific aspects and operation procedures have been identified and validated in the research project for the implementation of the 3D-IMP-ACT WebGIS platform and virtual tours. In particular, for the sake of brevity, the following discussion will be focused on the category of Architectures related to the medieval fortifications that are located along the Paths of Roman Routes - namely, Via Traiana in Italy, Via Egnatia in Albania and Via Flavia in Albania and Montenegro - where some GreekRoman archaeological Sites have been identified, as well (Figure 2).

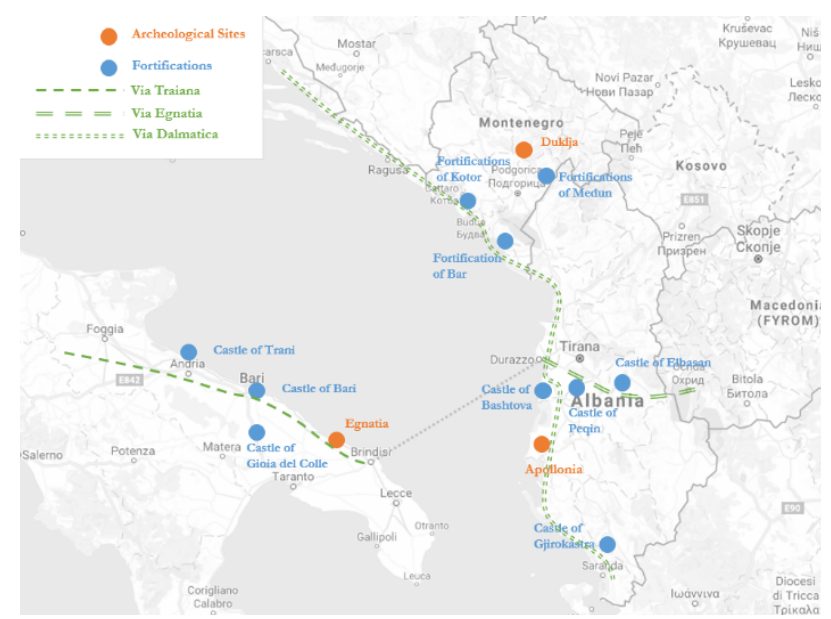

Figure 2. Case studies: Castles and Archaeological Sites.

Specifically, the pilot cases have been selected based on a SWOT analysis concerning historical, cultural and technical characteristics, as well as touristic flows, accessibility conditions, expectations by local communities, development strategies, funding perspectives and ongoing/foreseen restoration programs. Moreover, among all the pilot cases (Castles of Bari, Trani and Gioia del Colle in Apulia, Castles of Bashtova, Elbasan, Pequin and Gjirokastra in Albania, Castles of Kotor, Medun and Bar in Montenegro), some preliminary results are presented for the Castle of Trani.

\subsection{Web-GIS platform}

The WebGIS platform, which was elaborated from a Quantum GIS ${ }^{\circledR}$ project (QGIS Development Team, 2019), distributed by QGIS Server ${ }^{\circledR}$ and developed through a LIZMAP ${ }^{\circledR}$ plugin (D'Hont, R.L.. Douchin: M., 2014), has been based on a GeoDataBase elaborated in PostgreSQL (PostgreSQL Global Development Group, 2017) by its spatial extension Post GIS (PostGIS software Refractions Research, 2007). Thus, all infrastructures, composed of Geo-DB, GIS and Web-GIS, rely on open source software components. The relational Geo-DB layout offers an expandable system that might be enriched by further entities in the future - paths, architectures and sites beyond the project pilot-cases. Moreover, it enables the replication of the same contents by the Web Map Service (WMS) and Web Feature Service (WFS) technologies that allow for the dynamic representation of some maps from the spatial records, both as images and interrogable features, when queried on the Web. In fact, the underlying standards, that are elaborated by the Open Geospatial Consortium (OGS) (Vretanos P., 2016-10-26; De la Beaujardiere, J., 2006), address the distribution and interexchange of geo-spatial data. Thus, they can be accessed through both the project WebGIS and further Web platforms, with positive impacts on the dissemination of the project contents and the correlation and integration with other portals for several purposes. The Geo-DB layout has been conceived in order to fulfil the project's methodological framework. In fact, it allows for the storage of all the relevant records on the project entities within tables, which include useful information for both users and technicians and which relate the data hierarchically. For instance, the architectures and the sites represent the "father" of the highlights that are hosted in the DB. All the data are arranged according to a common structure, as both basic (Table 1) and detailed (Table 2) information, by means of free texts, single or multiple selection lists, photos and drawings. Similarly, for each typology, the highlights are identified univocally - for the Architecture Castles, they are Ante-wall, Harquebus hole, Bastion, Machicolation, Allure, Embrasure, Casemate, Courtyard, Loophole, Moat, Merlon, Drawbridge, Terre-plein, Tower - together with specific instructions for their description (Table 3).

\begin{tabular}{|l|l|}
\hline Field & Instructions \\
\hline Typology & $\begin{array}{l}\text { Select "Fortification, Church, Noble } \\
\text { Palace" }\end{array}$ \\
\hline Toponym & $\begin{array}{l}\text { Enter a name [text max 100 } \\
\text { characters] }\end{array}$ \\
\hline Coordinates & Enter coordinates \\
\hline Picture & Load a picture \\
\hline Foundation & Select "I-XX" and select "B.C., A.C." \\
\hline Accessibility & Select "Open, Closed, Partially Open" \\
\hline
\end{tabular}

Table 1. Instructions for Geo-DB basic data.

\begin{tabular}{|c|c|}
\hline Field & Instructions \\
\hline Current use & $\begin{array}{l}\text { Enter a description [text max } 100 \\
\text { characters] }\end{array}$ \\
\hline Surface & Enter a number \\
\hline Present property & $\begin{array}{l}\text { Select "Private, } \\
\text { Private/Public" }\end{array}$ \\
\hline Listed Building & Select "Yes, No" \\
\hline Historic Info & $\begin{array}{l}\text { Enter a description [text max } 3000 \\
\text { characters] }\end{array}$ \\
\hline $\begin{array}{l}\text { Historic Picture/ } \\
\text { Drawing } 1\end{array}$ & Load a picture \\
\hline $\begin{array}{l}\text { Picture/ Drawing } 1 \\
\text { capture }\end{array}$ & $\begin{array}{l}\text { Enter a description [text max } 200 \\
\text { characters] }\end{array}$ \\
\hline$\ldots$ & \\
\hline $\begin{array}{l}\text { Historic Picture/ } \\
\text { Drawing } 20\end{array}$ & Load a picture \\
\hline $\begin{array}{l}\text { Picture/ Drawing } \\
20 \text { capture }\end{array}$ & $\begin{array}{l}\text { Enter a description [text max } 200 \\
\text { characters] }\end{array}$ \\
\hline Architectural Info & $\begin{array}{l}\text { Enter a description [text max } 3000 \\
\text { characters] }\end{array}$ \\
\hline $\begin{array}{l}\text { Type of vertical } \\
\text { structures }\end{array}$ & $\begin{array}{l}\text { Multiple Select "Masonry, } \\
\text { Framework, Mixed" }\end{array}$ \\
\hline $\begin{array}{l}\text { Materials of } \\
\text { vertical structures }\end{array}$ & $\begin{array}{l}\text { Multiple Select "Stone, Brick, } \\
\text { Concrete, Timber, Other" }\end{array}$ \\
\hline $\begin{array}{l}\text { Type of horizontal } \\
\text { structures }\end{array}$ & Multiple Select "Vault, Slab, Other" \\
\hline $\begin{array}{l}\text { Materials of } \\
\text { horizontal } \\
\text { structures }\end{array}$ & $\begin{array}{l}\text { Multiple Select "Stone, Iron/Brick, } \\
\text { Concrete/Brick, Timber, Other }\end{array}$ \\
\hline $\begin{array}{l}\text { Type of roof } \\
\text { structures }\end{array}$ & $\begin{array}{l}\text { Multiple Select "Pitched roof, Flat } \\
\text { roof, Dome, Missing, Other }\end{array}$ \\
\hline $\begin{array}{l}\text { State of } \\
\text { conservation }\end{array}$ & Select "Poor, Fair, Good, Excellent" \\
\hline
\end{tabular}

Table 2. Instructions for Geo-DB detailed data. 


\begin{tabular}{|l|l|}
\hline Field & Instructions \\
\hline Highlight & $\begin{array}{l}\text { Select "Ante-wall, Harquebus hole, } \\
\text { Bastion, Machicolation, Allure, } \\
\text { Embrasure, Casemate, Courtyard, } \\
\text { Loophole, Moat, Merlon, } \\
\text { Drawbridge, Terre-plein, Tower" }\end{array}$ \\
\hline Toponym & $\begin{array}{l}\text { Enter a name [text max 100 } \\
\text { characters] }\end{array}$ \\
\hline Picture & \begin{tabular}{l} 
Load a picture \\
\hline Picture capture
\end{tabular} \\
\hline
\end{tabular}

Table 3. Instructions for the description of the highlights.

The main strengths of the WebGIS platform include its ease in population and access management. In fact, the WebGIS project is replicated by the LIZMAP plugin from a desktop QGIS project, with contents and characteristics specifically customized for the plugin itself, whereas all the data are arranged and stored within the Geo-DB. Once the functions of visualization and interrogation are optimized, they portray a template in which the real-time implementation of the Geo-DB automatically expands and modifies all the contents of the platform. Furthermore, the database might be visualized through different interfaces, such as a desktop project, referring to the same data, the DB interface and the web interface. DB and WebGIS also involve different roles and user profiles, with specific access keys for some authorized stakeholders - in this case, project partners that can interact, change and create new contents. Thus, the DB population directly affects the exploration of the WebGIS, which is the first "gate" for expert and non-expert users to access the places and relative informational contents.

Starting from the initial overview (Figure 3), the user can inquire into each entity - path, architecture or site - by parametric or spatial interrogation (Figure 4), based on the toponym or a free search on the objects (Figure 5). Moreover, he/she can access and explore the added contents, such as the highlights, related to a specific architecture/site.

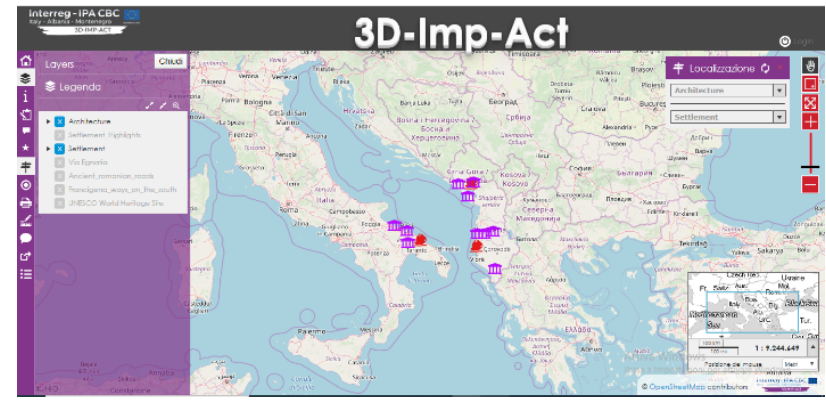

Figure 3. Initial overview of the WebGIS project.

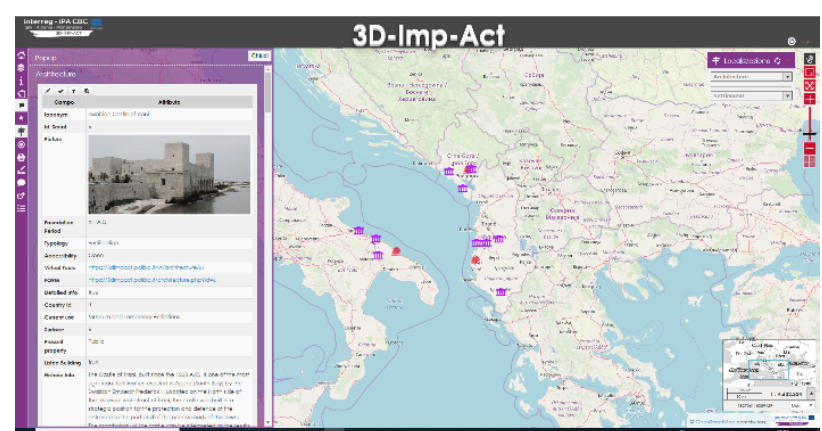

Figure 4. Example of pop-up with contents related to the Architecture Castle of Trani.

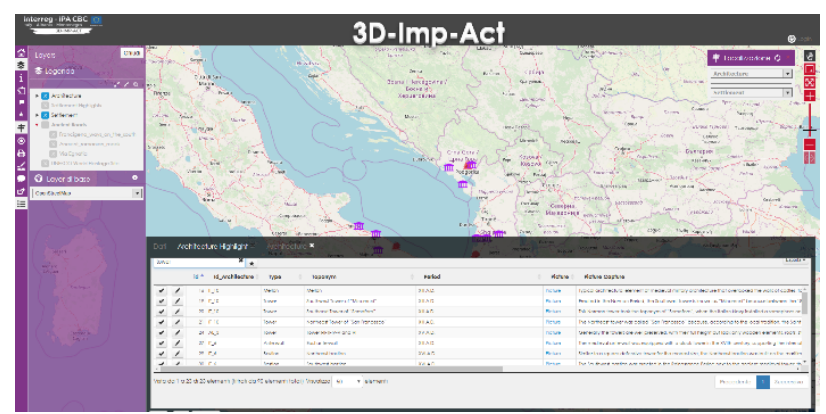

Figure 5. Example of search on the entity architecture and related highlights.

\subsection{Virtual tour augmented by hot spots and highlights}

From the WebGIS platform, users can access a virtual tour of $360^{\circ}$ spherical pictures, captured by panoramic head Manfrotto SKU 303SPH and elaborated by software Easypano Tourweaver ${ }^{\circledR}$, as well as to a series of multimedia contents in the form of web-based external links hosted by the tour itself. Specifically, the hot spots have been developed as follows:

- Schemes and models of the historical evolution (Timeline) are graphic restitutions of the main transformation phases of the fabrics, developed by software SketchUp Pro ${ }^{\circledR}$ and/or CAD representations of missing parts, that are documented by available archivist and bibliographic sources;

- Audio-video contents (Media) are shootings by Unmanned Aerial Vehicles (UAVs), namely by a DJI Inspire T600 drone equipped with X3 FC35 camera, in order to make visible some areas with limited accessibility, such as roofs and rooms that are closed to the public, areas with hazardous conditions or areas with physical obstacles;

- Three-dimensional models of relevant parts $(3 D)$ are photorealistic restitutions of architectural details, ultimately performed high off the ground level, elaborated by software Agisoft Photoscan ${ }^{\circledR}$ as coloured point clouds, from highresolution pictures, acquired by Canon EOS M3 24.2 camera;

- The thematic maps and experimental data related to the state of conservation (Diagnostic) offer tools for the investigation and assessment of cracks, dampness patterns and surface alteration, and include technical reports on thermography survey, radar scanning and sonic/ultrasonic testing.

The WebGIS contents are directly connected with the virtual tours by the highlights. Thus, from the exploration of one site/architecture, the users can return to the geographical system and visit another node of the network, with the possibility of gaining multiple access thanks to the optimization of different and coordinated environments.

\section{RESULTS}

In this section the described tools and contents are illustrated by discussing some preliminary results related to the Castle of Trani. This monument, which was built between 1233 and 1249 under Fredrick II of Swabia, was further fortified in the XVI century under Charles $\mathrm{V}$ of Bourbon, in order to defend the premises against the pressing advance of the Turkish Army along the Mediterranean coasts. Later, it was used as a prison in the XIX century. 
The current configuration of the Castle is the result of the abovementioned evolution phases. In fact, the Castle shows the typical medieval plan of a regular quadrangle arranged around the central courtyard, with square towers at the corners. Moreover, it is characterized by the characteristic elegance of Romanesque cornices, sculptural brackets and bas-reliefs. Moreover, the erection of two imposing bastions at the north-east and southwest corners, the thickening of the boundary walls and the construction of the moat surrounding the structure on three sides, with the fourth side directly overlooking the sea, are signs of its sixteenth-century transformation. The partial reconfiguration of the central courtyard, with the closure of the northern portico and the addition of a monumental staircase on the southern side, also dates back to the Bourbon phase. Finally, the traces of its use as a prison were almost completely removed during the restoration works carried out forty years ago by the then Superintendence of Puglia, to which the property had been transferred in 1976. Only in some points, the holding cells are still visible, having been left as a testimony of its previous use.

The current state of conservation is substantially good, except for the constant exposure of the stone facades to the marine environment, which in some cases involves the physicalmechanical degradation of the material.

As far as the project is concerned, the Castle, one of the nodes of the "virtual" network in the WebGIS platform, can be visited remotely by a virtual tour, including the most representative areas. From the scene of the entrance, close to the drawbridge on the east side, the visitor can interact with some standard navigation buttons, including links to the plan of the building with direct connection points to all the available scenes, as well as to the legend of all the icons used for hot spots and highlights throughout the tour (Figure 6).

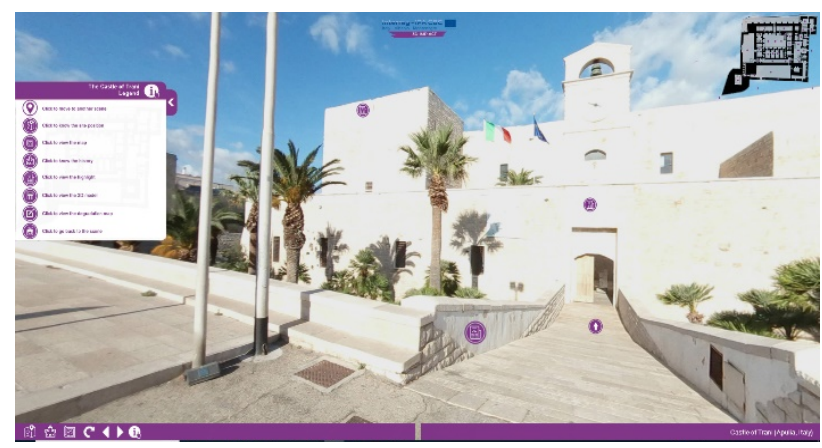

Figure 6. Scene of the drawbridge with active "site map" (top right) and "legend of icons" (left).

Nevertheless, some general hot spots enable the consultation of a datasheet, generated by the PostGis DB concerning the historical, architectural and technical characteristics (Figure 7), as well as the "media" contents with videos by drone showing the inaccessible roofs (Figure 8) and north façade on the sea (Figure 9), as well as the "Timeline" schemes on the historical evolution of the structure (Figure 10).

Thus, through the navigation, the user can also view some "3D" models, in this case mainly representing some sculptural decorations at the top of the walls for a close-range fruition (Figure 11) and some parts of the external masonry walls of the courtyards.

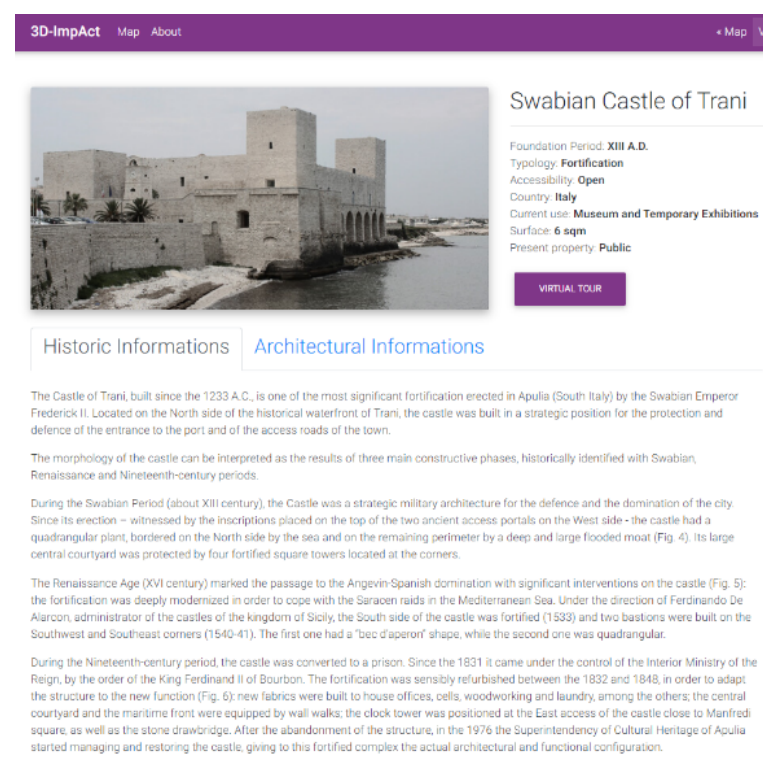

Figure 7. Datasheet, generated by the PostGis DB, on the historical, architectural and technical characteristics of the Castle.

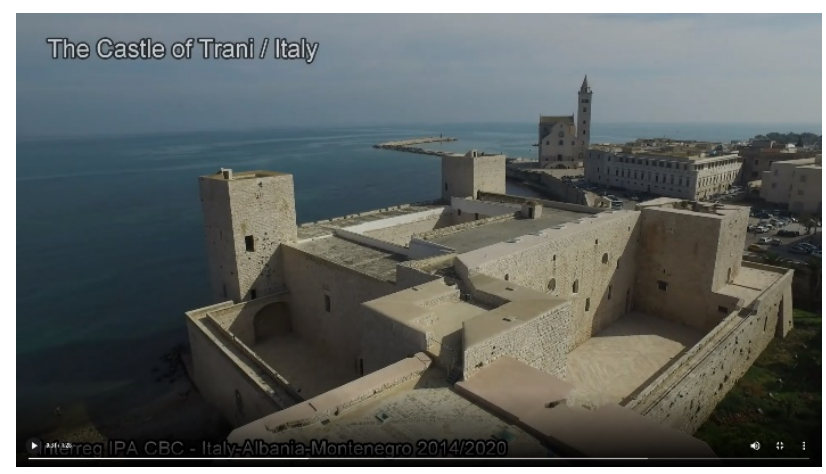

Figure 8. Screenshot, from active "Media" hotspot, showing the inaccessible roofs.

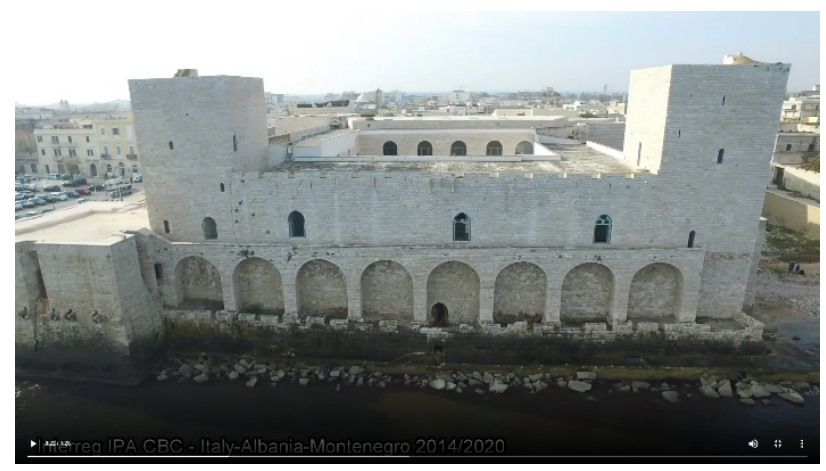

Figure 9. Screenshot, from active "Media" hotspot, showing the inaccessible north façade on the sea 


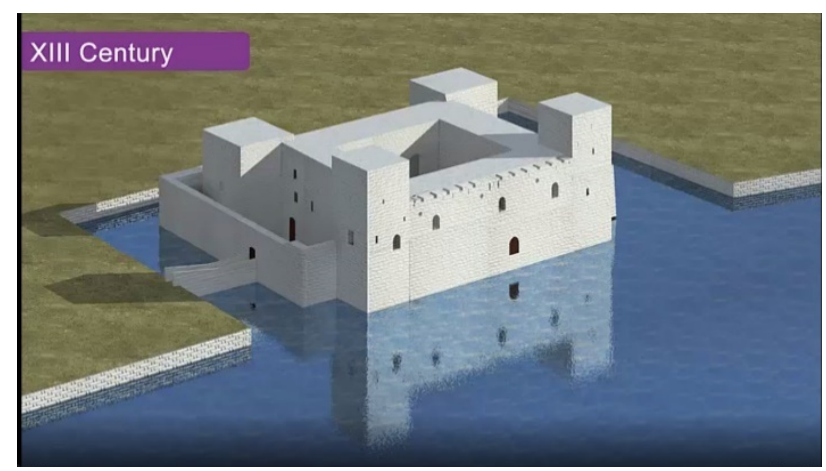

Figure 10. Screenshot, from active "Timeline" hotspot, showing the Medieval configuration of the castle.

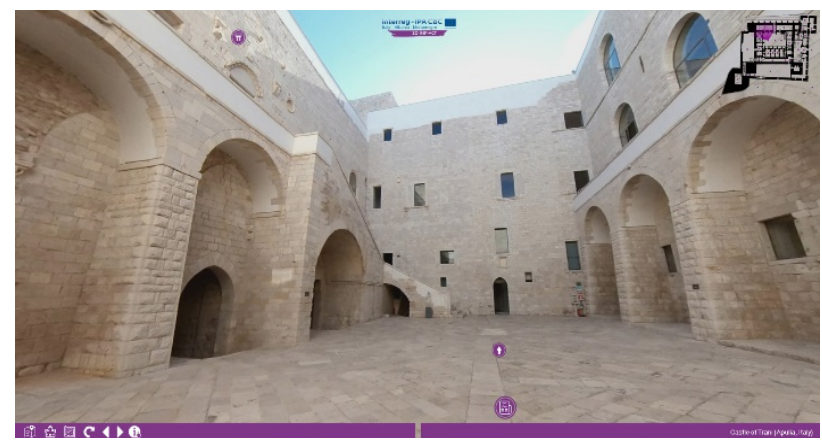

Figure 11. Scene of the central courtyard with "3D" icons close to some capitals (top left).

The 3D models of the of the external masonry walls of the courtyards are also used as a base for the "Diagnostic" thematic maps, showing the stone decay of the facades that are more exposed to the aggressive marine environment.

The decay maps are based on the taxonomy of the Italian code UNI 11182 "Cultural heritage. Natural and artificial stone. Description of the alteration - Terminology and definition", as well as on the international guidelines "ICOMOS-ISCS. Illustrated glossary on stone deterioration patterns". However, in the present study, the textures, as reported in the code UNI 11182, are displayed with coloured layers, in order to make them more visible on the underlying image (Figure 12).

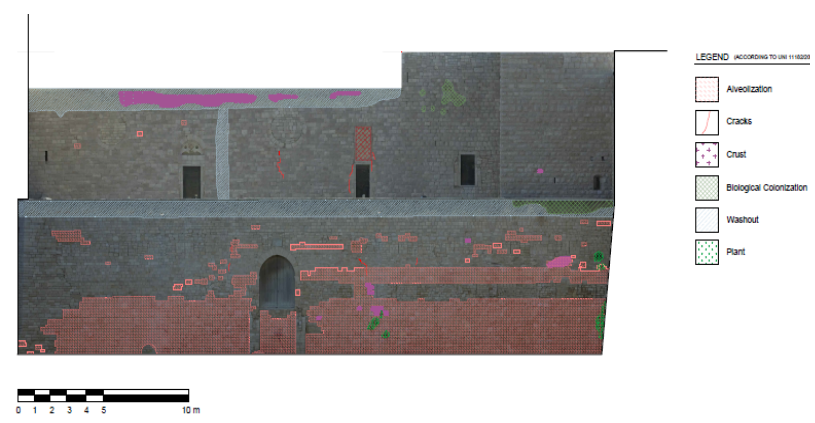

Figure 12. Example of decay map.

Furthermore, with reference to the "3D" and "Diagnostic" contents, the platform offers great possibilities of appreciation. In fact, the three-dimensional models and thematic maps can be seen in two different views.
The first is related to "static", or read-only, images/videos about the process which convert the pictures into textured polygonal meshes (Figure 13). The second relates to "dynamic" objects, where the coloured point clouds are scaled and referenced and they might be interrogated, in a web viewer, such as Potree ${ }^{\circledR}$, with functions of measurement and annotations for more specialized elaborations (Figure 14).

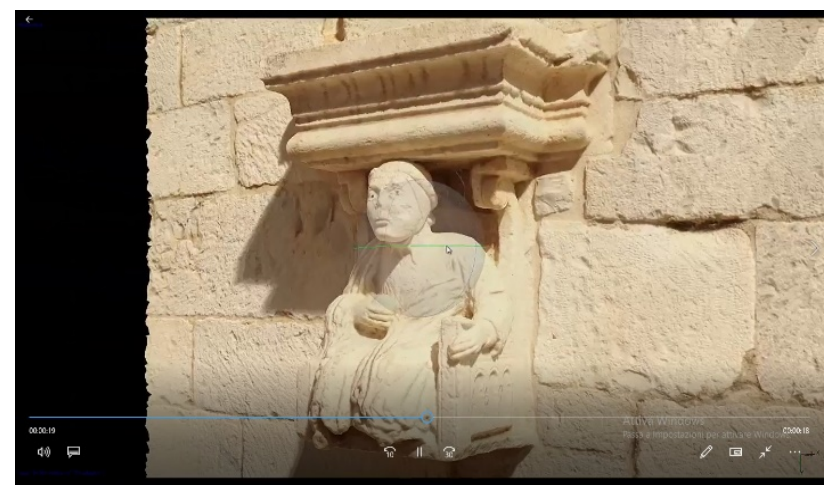

Figure 13. Screenshot, from active "3D" hotspot, showing a read-only video of the textured polygonal meshes of a capital.

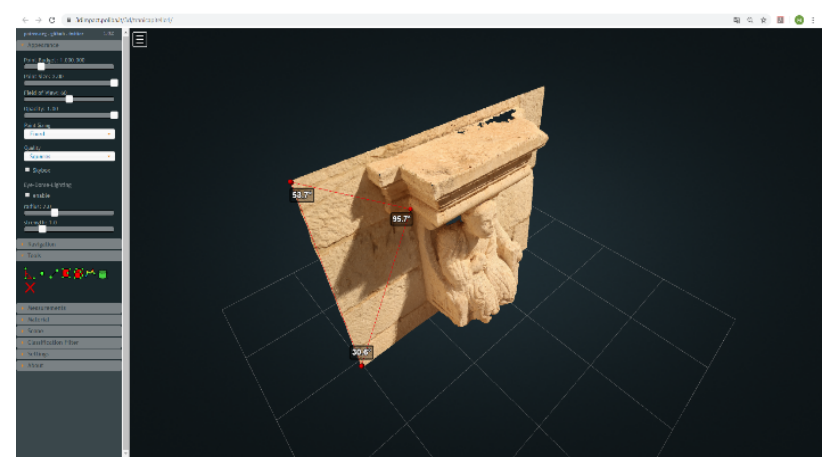

Figure 14. Screenshot, from active "3D" hotspot, showing point clouds of a capital in a web viewer.

Finally, corresponding to each highlight (Figure 15), the relative icon links to a data sheet, including a picture and a few lines of description of the architectural/sculptural detail, as well as to a list of all the other highlights of the same type (e.g. tower) in the same Castle and in all the other pilot-cases (Figure 16).

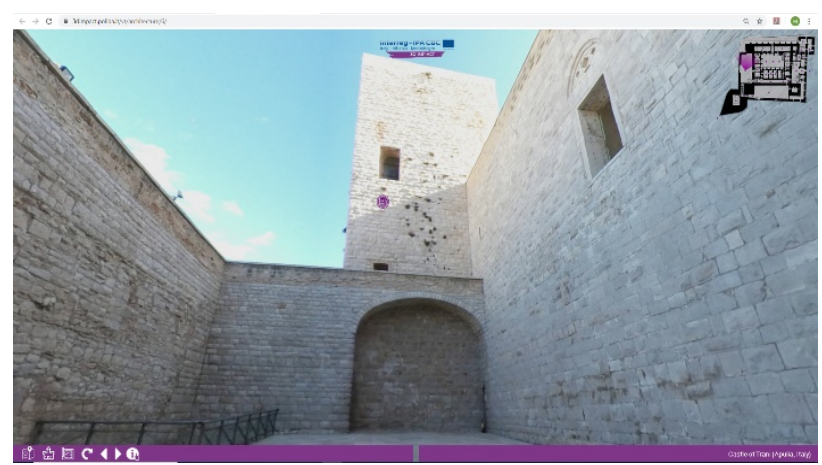

Figure 15. Scene of the west courtyard with active "North-East Tower" highlight. 

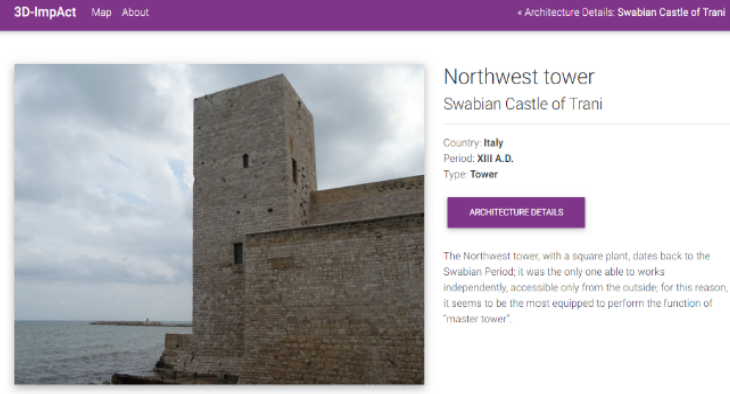

Related Highlights

Type: Tower
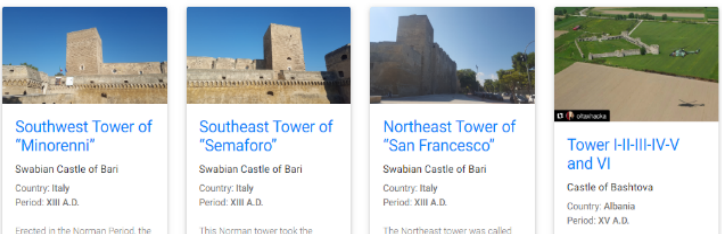

Figure 16. Data sheet of the "North-East Tower", followed by a list of the project towers.

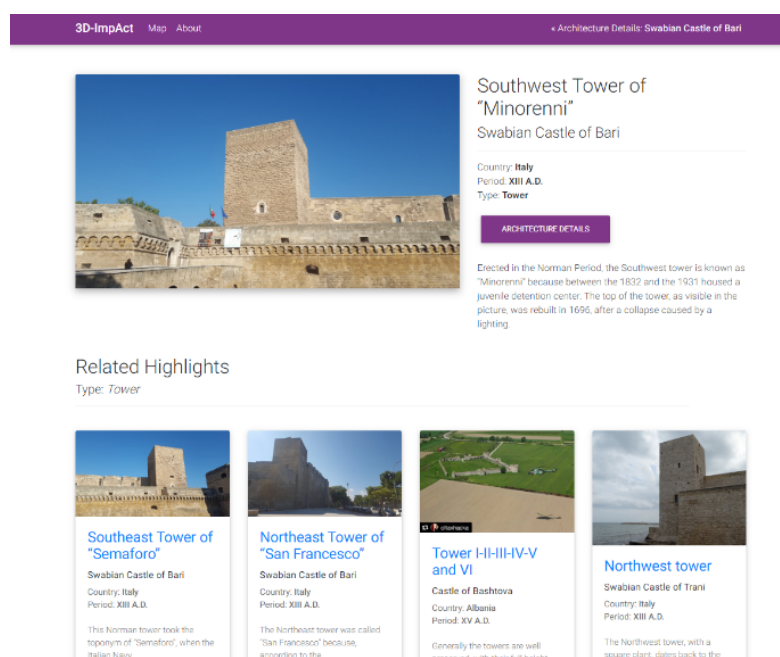

Figure 17. Short description of the "South-West Tower" of the Castle of Bari from the list of the project towers, as in Figure15.

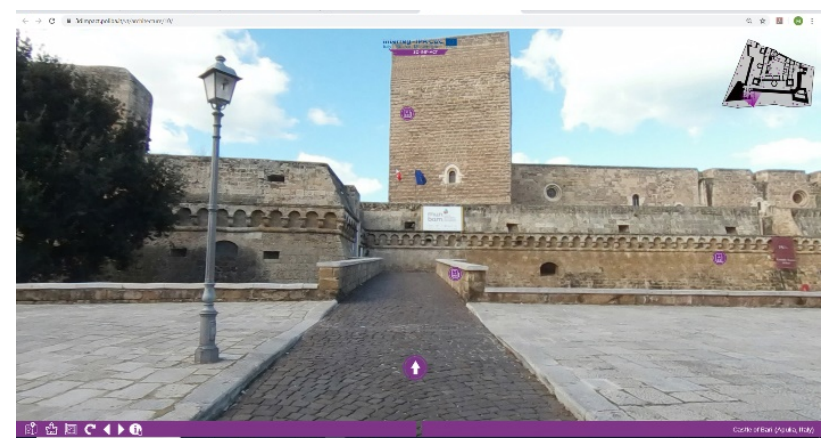

Figure 18. Opening scene of the virtual tour of the Castle of Bari, activated from the short description, as in Figure16.
Each datasheet is hosted within a dynamic web page, generated by scripts on HYYPS server on request by the client via his/her internet browser. The scripts run connections to the Web-GIS DB that allow the informational fields of the highlight to be read. Thus, the information is displayed according to a pre-defined template.

At the same time, a query to the DB is executed in order to identify all the other highlights belonging to the same type. These other highlights are presented as a list of hypertextual links, featured by toponym and image for immediate identification. By clicking on a link in the list, the user is directed to the associated data sheet (Figure 17) and, thus, to the virtual tour of the related case study (Figure 18).

\section{CONCLUSIONS}

The methodological workflow for the implementation of the WebGIS platform and the virtual tours augmented with multimedia and multi-thematic tools has been developed to allow the interactive exploration of a semantically consistent set of assets of the architectural and archaeological heritage at territorial scale, especially for touristic purposes.

Nevertheless, it shows a flexibility with regard to its tools and procedure, due to its transversal systematization and interrogation of specialist contents within the WebGIS DB that make it suitable for technical purposes as well.

In particular, in light of the assessment and control of the state of conservation of fabrics and sites, more specific criteria - such as technical-technological characteristics of masonry structures, functional uses, material-formal peculiarities of the decoration elements, and so on - might be used for the identification of the categories. Similarly, the hot spots and highlights might be addressed to include specialized aspects - e.g. highlights on decay patterns, conservation treatments, monitoring techniques, operation instructions for the restoration workers, and so on.

Such a technical declination would certainly support the stakeholders of the conservation and safeguard the sites and architectures in question, and in two ways: first, by structuring, correlating and sharing an extraordinary variety of different data, in terms of type and theme, on a single case; and, second, by enabling the correlated and integrated analysis, even on different cases, as support for updating the knowledge from "preliminary" to "consolidated".

\section{ACKNOWLEDGMENTS}

This research was supported by the project Interreg-IPA CBC Italy-Albania-Montenegro 3D-IMP-ACT/No. 314 "Virtual reality and 3D experiences to IMProve Attractiveness, Cultural heritage smart management and Touristic development".

\section{AUTHOR CONTRIBUTIONS}

Although all the authors have all cooperated in the conception of the work and the acquisition, analysis and interpretation of data, the following individual contributions apply to the manuscript: 1 . Introduction: MDF and CC, 2. Methodology: MDF, 3.1 WebGIS platform; CC; 3.2 Virtual tour augmented by hot spots and highlights: MDF; 4. Results: MDF; 5. Conclusions: FF. 


\section{REFERENCES}

Arca, D., Şeker, D. Z., Alkan, M., Karakış, S., Bayık, Ç., Acar, H., 2018. Development of Web-Based GIS for the Cultural Heritage of Safranbolu, Turkey. International Journal of Environment and Geoinformatics, 5(3), 368-377.

Barelli, L., Paolini, P., \& Forti, G., 2017. The XII Century Towers, a Benchmark of the Rome Countryside almost cancelled the Safeguard Plan by Low Cost Uav and Terrestrial Dsm Photogrammetry Surveying and $3 d$ Web GIS Applications. Int. Arch. Photogramm. Remote Sens. Spatial Inf. Sci, 42, 17, Proceedings of 5th International Workshop LowCost 3D Sensors, Algorithms, Applications, Hamburg, Germany.

Campanaro, D. M., Landeschi, G., Dell'Unto, N., Touati, A. M. L., 2018. 3D GIS for cultural heritage restoration: A 'white box'workflow. Journal of Cultural Heritage, 18, 321-332.

De la Beaujardiere J. (ed.), OpenGIS ${ }^{\circledR}$ Web Map Server Implementation Specification1.3.0, OGC Document \#006042,15/03/2006 3. Available online from https://www.opengeospatial.org/docs/is/

D'Hont, R.L., Douchin, M. Lizmap software, 2014. Avalaible online from http:/www.3liz.com/lizmap.html

Ferreira Lopes, P., 2018. Achieving the state of research pertaining to GIS applications for cultural heritage by a systematic literature review. Int. Arch. Photogramm. Remote Sens. Spatial Inf. Sci, 42 (4), 169-175.

Li, R. Y. M., 2017, 5D GIS virtual heritage. Procedia computer science, 8th International Conference on Advances in Information Technology, IAIT2016, 19-22 December 2016, Macau, China, 111: 294-300.

Malfitana, D., Cacciaguerra, G., Mazzaglia, A., Barone, S., Noti, V., 2016. OpenCiTy Project. Open Data, GIS, webGIS per l'archeologia urbana e il patrimonio culturale di Catania, Archeologia e Calcolatori, (S.8), 150-161.

Marques, L., Tenedório, J. A., Burns, M., Romão, T., Birra, F., Marques, J., Pires, A., 2017. Cultural Heritage 3D Modelling and visualisation within an Augmented Reality Environment, based on Geographic Information Technologies and mobile platforms. Architecture, City and Environment, 11(33), 117-136.

PostgreSQL Global Development Group. Retrieved March 14, 2017. Available online from https://www.postgresql.org/

PostGIS software Refractions Research, 2007. Available online from http://www.postgis.org

QGIS Development Team, 2019. QGIS Geographic Information System. Open Source Geospatial Foundation Project. Available online from http://qgis.osgeo.org

Scianna, A., La Guardia, M., 2018. Globe Based 3D GIS solutions for Virtual Heritage, Int. Arch. Photogramm. Remote Sens. Spatial Inf. Sci, 42 Volume XLII-4/W10, Proceeding of 13th 3D GeoInfo Conference, Delft, The Netherlands.

Trizio, I., Savini, F., Giannangeli, A., 2018. Integration of trheedimensional digital models and 3D GIS:the documentation of the medieval burials of Amiternum (L'Aquila, Italy). Int. Arch. Photogramm. Remote Sens. Spatial Inf. Sci, 42(2).
Von Schwerin, J., Richards-Rissetto, H., Remondino, F., Agugiaro, G., Forte, M., Maqueda, R., 2011. The MayaArch3D Project; Digital Technologies for Research in Maya Archaeology. Final Performance Report and White Paper for NEH Digital Humanities Level II Start-Up, Grant.

Vacca, G., Fiorino, D., Pili, D., 2018. A spatial information system (SIS) for the architectural and cultural heritage of Sardinia (Italy). ISPRS International Journal of GeoInformation, 7(2), 49.

Vretanos, P. (ed.), OGC Web Feature Service Implementation Specification with Corrigendum 1.0.0, OGC Document \#04094r1, 2016-10-26. Available online from World Wide Web: https://www.opengeospatial.org/docs/is/ 